\title{
Entrevista com Heloísa Buarque de Hollanda - Feminismos em pleno voo: multiplicidade, protagonismo e transformação social
}

Interview with Heloísa Buarque de Hollanda - Feminisms in full flight: multiplicity, leadership and social change

Heloísa Buarque de Hollanda ou Helô, como é chamada na conversa, se integrou ao corpo docente da Escola de Comunicação da UFRJ em 1970 e, no início, deu aulas de estética cinematográfica e prática de fotografia. No memorial que escreveu em 1993 para o concurso de professora titular em Teoria Crítica da Cultura, descreve como fez a transição para a ECO das Letras, pois se formou em Letras Clássicas e fez mestrado e doutorado e deu aula por muitos anos na Faculdade de Letras da UFRJ. Em meados dos anos 1960, diz, lendo Walter Benjamin em aula com José Guilherme Melquior, "a compreensão que tinha dos marcos de minha área de estudos fragilizava-se e começava a perceber, com e através de Benjamin, uma prática crítica contagiada por redes discursivas praticamente ilimitadas". Esse impacto e o da leitura de Roland Barthes levaram Heloísa à ECO e, no encadeamento do texto do memorial, conduz ao relato de uma conversa com Ria Lemaire, medievalista da universidade de Utrecht. "Nos demos conta de que ambas, por muito tempo, experimentamos uma sintomática paralisia diante do que percebíamos como sendo o iluminado panteão dos grandes pensadores ocidentais. Um horizonte inexplicavelmente distante. É importante a troca de experiências entre as mulheres. É importante a conversa entre nós”. Impossível não perceber, no encadeamento de pensamento que começa com Benjamin, a reflexão contextualizada característica de Heloísa e que inclui o exercício da simpatia e a leveza lúdica. 
Heloísa está em constante movimento e quando algo ou alguém a faz parar, ela disse alguma vez, sua atitude é "mais trabalho". Isso e sua rebeldia, pelo menos tríplice, nos dizem respeito como feministas na universidade hoje: rebeldia contra os confinamentos de disciplinas, contra o superego paralisante constituído pelos grandes pensadores europeus e contra a solidão da competição sem as trocas que sempre são mais possíveis entre mulheres. Cada coeditora (Maria Bogado, Lígia Lana, Liv Sovik) contribuiu com as perguntas enviadas para Heloísa e que ela prontamente respondeu por escrito. Quando as leitoras conferirem, poderão verificar que ela continua no encalço da alegoria que primeiro pensou com Benjamin e através dele. A alegoria, a classicista informa no memorial, vem do grego állos "outro/outra" + agoreúō "falar em público", que Heloísa traduz como "dizer o outro". Com a entrevista, nós, as editoras, pudemos entrar no jogo de Helô, o de provocar a fala: na revista ela foi a nossa alegoria (e nossa alegria), como é há tanto tempo, para tanta gente.

Liv Sovik, Lígia Lana e Maria Bogado

\begin{abstract}
$* * * * * *$
Você sempre foi atenta e crítica em relação ao papel do intelectual na sociedade. Como a descoberta e permanente revisão dos feminismos te afetou no modo de conceber e praticar suas atividades intelectuais?
\end{abstract}

Heloísa Buarque de Hollanda: Talvez essa última revisão do feminismo tenha sido o impacto mais radical que sofri enquanto ativista acadêmica. Ao ser levada a perceber que meu papel de feminista "universal", branca e heterossexual, me fazia normativa e mesmo me ensurdecia em relação à diversidade das opressões das muitas mulheres não brancas e não heterossexuais, tive que mudar radicalmente minhas estratégias políticas e acadêmicas. A difícil tarefa de dividir e compartilhar meus privilégios de fala e de poder tornou-se minha mais importante ação política. 
Confesso que se saber sujeito do racismo e das diversas exclusões de gênero foi um choque irreversível e ainda estou tentando as muitas formas de lidar com isso.

Gostaria que você comentasse quais podem ser os impactos dos feminismos na universidade. Além das importantes contribuições epistemológicas, como você sente que os feminismos apresentam variações nos métodos de pesquisa, nas formas textuais e mesmo nos modos de conviver em sala de aula ou em outros espaços de compartilhamento de saber?

HBH: A universidade foi criada a partir de um paradigma branco e masculino. Esse paradigma foi constitutivo dos códigos que formatam a produção e as avaliações de legitimidade da ciência e do conhecimento. Entre esses códigos, chamo atenção para o da objetividade (seja o que se quer que isto signifique) como um de seus operadores mais potentes. É o que se vê, até hoje, no universo das grandes narrativas de explicação do mundo, da sociedade e da ciência. Por outro lado, as próprias formas acadêmicas e científicas de construção da ordem burocrática, do estabelecimento de hierarquias, dos sistemas de progressão de carreira e das lógicas curriculares obedecem ao mesmo paradigma, fortalecendo e mesmo amarrando estruturalmente o sistema da produção de conhecimento. A chegada dos feminismos nessa estrutura pode ser devastadora. Se conseguirmos a chancela para novos pontos de vista e para que novas experiências sociais surjam como legítimas e capazes de produzir conhecimento, certamente veremos a multiplicação de metodologias, de novos campos de pesquisa, novos desenhos de objetos de reflexão até hoje impensáveis, e, sobretudo, uma estrutura institucional mais democrática.

Você sempre fala que "o cânone é surdo". Poderia explicar por que? Ainda tomando como base o campo acadêmico, você tem escutado alguma surdez forte no momento atual?

HBH: Sempre percebi isso. São vários os comportamentos que se repetem. A negação da transformação que se anuncia, ora como "moda passageira", ora 
através de um pensamento redutor que adapta o novo ao já conhecido. Essas as mais frequentes reações. Raramente ouve-se na academia: "eu não sei nada sobre isso, vamos escutar mais um pouco". Ou mesmo vamos a campo. Alguns motivos podem ser aventados: o não reconhecimento da falta de instrumentos para lidar com um objeto/campo novo; a falta visceral de curiosidade pelo desconhecido; o perigo de arriscar o próprio capital acadêmico. Aí voltamos à pergunta anterior. A universidade não tem flexibilidade para improvisar/arriscar com instrumentos de análise. 0 trabalho acadêmico, para ser legitimado, tem que provar a "qualidade" e a "objetividade" de seu acervo teórico, preferencialmente eurocentrado. 0 risco e o erro, para mim oportunidades experimentais irresistíveis, não têm "assento" no trabalho acadêmico. 0 cânone, por mais valioso que seja, e provavelmente por isso mesmo, é surdo à moda de Ulisses em seu confronto com as sereias. Hoje, não está querendo ouvir, por exemplo, o canto evangélico em populações de baixa renda.

Como poderíamos hoje, no Brasil, avaliar a ideia de Virginia Woolf, de que "uma mulher precisa ter dinheiro e um teto todo seu, se quiser escrever ficção"? As mulheres brasileiras possuem essas condições apontadas por Woolf para produzirem seus textos? Não somente na literatura de ficção, como também na produção cinematográfica e audiovisual, na literatura de nãoficção, nas artes?

HBH: Virginia Woolf se expressou, magnificamente, num momento em que as mulheres nem às universidades tinham acesso. A independência feminina apoiada em educação e renda própria era sonhada e desejada por mulheres que tinham uma vida confortável, de alta classe média, como era o caso de Virgínia. Eu diria que o quadro hoje em plena crise do capitalismo sob a égide neoliberal da globalização é bem outro. As desigualdades sociais, o desemprego e a vulnerabilidade social aumentaram em proporção geométrica, a literatura, além de ser uma profissão nobre, passa a ser também um canal de expressão política urgente e inadiável. É muito interessante observar a flexibilização da função social da literatura. Hoje, especialmente nos segmentos mais pobres, a literatura ganha 
força e se multiplica em livros independentes, saraus, slams, raps , lambe lambes, e invade o grafite. Estamos num outro quadro, bem diverso do teto necessário à Virgínia, bem como da sua aspiração à independência e autonomia. São as mulheres precarizadas que mais recorrem à literatura, com a urgência de discutir questões fundamentais de suas vidas em espaços preferencialmente públicos. Sim, a produção literária (ou cultural) realizada por mulheres bem situadas hoje seria ainda uma grande meta ou mesmo demanda importante. Mas o movimento cultural das mulheres também nos mostra que mesmo sem recursos e valorizando o espaço publico, as novas escritoras e poetas estão sabendo exercer de forma, não menos esplêndida, o direito de se expressar e se afirmar neste quadro politico social tão adverso às suas demandas e sonhos.

Você escreve, no final de Escolhas (2009), sobre a influência em você de Rachel de Queiroz. Ela "desmontou não só minha ingênua aplicação dos modelos teóricos europeus e norte-americanos na análise das escritoras brasileiras, como tornou muito mais complexa a minha visão das oligarquias brasileiras". Que complexificação foi essa?

Não posso falar muito sobre isso porque, infelizmente, não cumpri a trajetória de estudos que me atraiu naquele momento. Mas chegando perto de Rachel, observando e tentando entender os caminhos de seu ativismo comunista nos anos 30, trotskista nos 40 e conservador na década de 1960, pude perceber que a lógica de poder do que poderíamos chamar de Brasil Profundo é estruturalmente diversa daquela do Brasil do litoral. A formação das famílias, a distribuição de poder entre seus elementos, entre a Igreja e a família, entre o Estado e a família, e as múltiplas variáveis que surgem e se entrelaçam nos oferece um campo de entendimento das oligarquias um pouco desnorteante. Eu percebi que o estudo da história social do Brasil interiorano, aquele do sertão é fonte fundamental para o entendimento do Brasil como um todo. Encarei uma enorme bibliografia, iniciei uma pesquisa sobre 
as matriarcas nordestinas, mas as pressões de nossas vidas profissionais acabaram me levando em outras direções. Um pena.

Dá para sentir um acerto de contas com o feminismo, na enxurrada de livros que você fez nos últimos três anos. Como você vê o futuro?

HBH: Vejo o feminismo em pleno voo em direção à ampliação de seus campos de atuação. Vejo, sobretudo entre nós, depois de um período de lutas identitárias e focadas na representação, a recuperação do ethos de transformação social que marcou os ativismos dos anos 60/70. Vejo a imagem de um feminismo múltiplo onde as varias etnias, raças e opções de gênero entram em diálogo, em busca de consensos e de lógicas mais comunitárias. Vejo um feminismo já atento ao caráter estrutural e institucional do racismo e do sexismo de nossa cultura. Vejo um feminismo protagonizando transformações amplas e decisivas que serão a marca deste século XXI. 